\title{
Big Data Matching Using the Identity Correlation Approach
}

\author{
McCormack, Kevin and Smyth, Mary
}

Methodology Division, Central Statistics Office, Cork, Ireland

\begin{abstract}
The Identity Correlation Approach (ICA) is a statistical technique developed for matching big data where a unique identifier does not exist. This technique was developed to match the Irish Census 2011 dataset to Central Government Administrative Datasets in order to attach a unique identifier to each individual person in the Census dataset (McCormack \& Smyth, 2015 ). The unique identifier attached is the PPS No. (Personal Public Service No. ${ }^{2}$ ). By attaching the PPS No. to the Census dataset, each individual can be linked to datasets held centrally by Public Sector Organisations. This expands the range of variables for statistical analysis at individual level. Statistical techniques developed here were undertaken for a major European Structure of Earnings Survey (SES) compiled by the CSO using administrative data only, and thus eliminating the need for an expensive business survey to be conducted (NES, 2007 $7^{3,4,5}$ ). A description of how the Identity Correlation Approach was developed is given in this paper. Data matching results and conclusions are presented here in relation to the Structure of Earnings Survey (SES) ${ }^{6}$ results for 2011.
\end{abstract}

Keywords: Identity Correlation Approach, Big Data matching, Unique identifier 


\section{Identity Correlation Approach}

The Identity Correlation Approach (ICA) was developed as part of a big data matching Project known as the SESADP (Structure of Earnings Survey Administrative Data Project) carried out by the Central Statistics office, Ireland (McCormack \& Smyth, 2015 ${ }^{1}$ ). The aim of the SESADP was to produce data to meet the EU SES 2014 Regulation from administrative data sources, from 2011 on an annual basis going forward. This eliminated the need for an expensive business survey to be conducted each year (NES, 2007 $7^{3,4,5}$ ).

The ICA involves combining a number of individual variables for each person until a

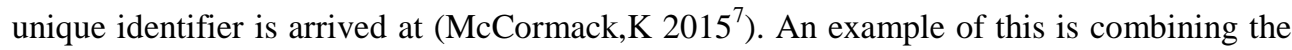
individual characteristics of each person in the Irish Census Dataset. Beginning with the variable for date of birth, then combine it with the variable gender, then adding variable for county, \& marital status, etc. until a unique identifier is arrived at for each person. This is illustrated in Figure 1 below.

\subsection{Theoretical Application}

There was $1.6 \mathrm{~m}$ employees in Ireland in 2011. Of these, an average of 65,000 persons were born in the same year (years 1946 to 1995), as illustrated in Figure 1.

Figure 1: Identity Correlation Approach: Simple Model - Combining Variables

\begin{tabular}{|llr|}
\hline Operation & Variable & No. of Records \\
\hline & Approx. No. of births each year & 65,000 \\
\hline Divide by: & No. days in the year & 365 \\
\hline & No. Persons with same DoB & 178 \\
\hline Divide by: & Gender & 2 \\
\hline & No. Persons with same DoB and gender & 89 \\
\hline Divide by: & No. Counties & 26 \\
\hline & No. Persons with same DoB, Gender, County & 3 \\
\hline Divide by: & Marital Status (married \& other) & 2 \\
\hline & $\begin{array}{l}\text { No. Persons with same DoB, Gender, County, marital } \\
\text { status }\end{array}$ \\
\hline
\end{tabular}


The 65,000 persons born in the same year are divided by 365 days in the year to give approximately 178 persons with the same date of birth. The 178 persons with the same date of birth (DoB) can be divided by 2 for gender, to give 89 persons with the same DoB and gender. Dividing by the no. of counties a person lives in ( 89 divided by 26) results in 3 persons with the same DoB, gender $\&$ county. The 3 persons can be further subdivided by marital status resulting in 1 person with the same DoB, gender, county and marital status. Other variables used to further breakdown the data are industrial sector ( $\mathrm{NACE}^{5}$ code), no. of dependent kids, etc. A unique combination of variables for each person allows a person to be uniquely identified. This method is termed the Identity Correlation Approach (ICA).

\subsection{Complexity and Variables Added}

Complexity added to the simple model for the Identity Correlation Approach is shown in Figure 2. Populations are not evenly distributed, thus we allow for the fact that up to a third of the working population may be based in Co. Dublin. As a result, duplicates increase 10 fold for the No. of persons with the same DoB, gender \& county. Similarly, the employee population is not evenly distributed in the various NACE sectors (industrial sector). Other variables added include no. of dependent children, which allows further breakdowns. In this way the Identity Correlation Approach arrives at a unique identity for each individual by combining a number of personal characteristics for the person.

Figure 2: Identity Correlation Approach: Complexity \& Variables Added

\begin{tabular}{|llr|}
\hline Operation & Variable & No. of Records \\
\hline & Approx. No. of births each year & 65,000 \\
\hline Divide by: & No. days in the year & 365 \\
\hline & No. Persons with same DoB & 178 \\
\hline Divide by: & Gender & 2 \\
\hline & No. Persons with same DoB and gender & 89 \\
\hline & No.Counties (allowing for approx. one third employees living in \\
Divide by: & Dublin) & 3 \\
\hline & No. Persons with same DoB, Gender, County & 30 \\
\hline & NACE industrial code (15) - allow for one fifth employees in same \\
Divide by: & NACE Sector & 5 \\
\hline & No. Persons with same DoB, Gender, County, NACE & 6 \\
\hline Divide by: & Marital Status (married \& other) & 2 \\
\hline & No. Persons with same DoB, Gender, County, NACE, marital status \\
\hline Divide by: & No. of dependent kids (3 groups) & 3 \\
\hline & No. Persons with same DoB, Gender, County, NACE, marital status, \\
no. dependent kids
\end{tabular}




\section{Practical Application}

\subsection{Census 2011 data}

The identity Correlation approach was applied to the Irish Census Data 2011 as described above. This allowed for a Unique Identifier (UI) to be applied to each individual by combining their personal characteristics (i.e. DoB, gender, county residence, etc.). The unique identifier is called the matching variable (matchvar) which is used to link each person's record to other datasets (see Fig. 3).

Figure 3: Applying Identity Correlation Approach to Create Unique Identifier (Matchvar)

\begin{tabular}{|c|c|c|c|c|c|c|}
\hline$\frac{\text { Date_of }}{\underline{\text { Birth }}}$ & $\underline{\text { Gender }}$ & County & $\underline{\mathrm{NACE}}$ & $\frac{\text { Marital }}{\underline{\text { Status }}}$ & $\underline{\text { No.Kids }}$ & $\begin{array}{c}\text { Matchvar } \\
\text { (all variables) }\end{array}$ \\
\hline 15031949 & M & CORK & 42 & M & 0 & 15031949MCORK42M 0 \\
\hline 11021945 & $\mathrm{~F}$ & LIMERICK & 31 & S & 1 & 11021945FLIMERICK31S1 \\
\hline 21111954 & M & DUBLIN & 25 & $\mathrm{D}$ & 2 & 21111954MDUBLIN25D2 \\
\hline 19051964 & M & CARLOW & 55 & $\mathrm{O}$ & 2 & 19051964MCARLOW55O2 \\
\hline 22091966 & M & GALWAY & 82 & M & 3 & 22091966MGALWAY82M3 \\
\hline 24031971 & $\mathrm{~F}$ & CAVAN & 84 & M & 0 & 24031971FCAVAN84M0 \\
\hline
\end{tabular}

\subsection{Public Sector Administrative Datasets (ADS)}

A single master Administrative Dataset (ADS) was created by linking a number of Public Sector Administrative Datasets (Revenue Commissioners Tax data, Social Security Administrative Datasets and the CSO's Administrative Datasets (e.g. Central Business Register (CBR), Earnings and Labour Force Survey)). These datasets were combined using the PPS No. for each individual and the CBR Enterprise No. for Establishment Surveys. The identity Correlation approach was applied to the master Administrative Dataset (ADS) also, allowing for a Unique Identifier (UI) to be applied to each individual by combining their personal characteristics (i.e. DoB, gender, county residence, etc.). This Unique Identifier known as the match variable (matchvar) was then used to link to the UI (matchvar) in Census.

\subsection{Linking Census to ADS}

Variables common to both the Census dataset and the master Administrative Data Source (ADS) were identified (e.g. DoB, gender, etc.). These common variables were joined to each other to create a Unique Identifier on each dataset using the Identity Correlation Approach. By linking the two datasets using the Unique Identifier, a PPS No. could be applied to each individual person in the Census. This is shown in Figure 3. Once the PPS No. was assigned to the Census dataset, it enabled Census data to be linked to any Public Sector Administrative Dataset. 


\section{Dataset Matching}

\subsection{Census dataset}

A total of 1.6 million employee records were extracted from the 4.6 million Census Records. Approximately 200,000 records had a unique Business No. identifier attached (CBR No.). Another 500,000 records had a CBR No. attached using the Employer's Business name on the Census. The first matching variable (Matchvar1) created for Census used the following variables combined: CBR No., Dob, gender, county, NACE 2, marital status, No. of kids. A second matching variable was created (Matchvar2) excluding NACE2 (see Figure 4). Up to ten matching variables (Matchvar1 - Matchvar10) were created. Each matching variable is similar to the previous one with one change to the composition variables for each subsequent matching variable created. Figure 4 illustrates the construction of each subsequent matching variable.

Figure 4: Matching Variables

\begin{tabular}{|c|c|c|c|c|c|c|c|c|c|}
\hline$\frac{\text { Date_of }}{\text { Birth }}$ & Gender & County & NACE & Ent No. & $\begin{array}{l}\text { Marital } \\
\underline{\text { Status }}\end{array}$ & No.Kids & Match Var 1 & Match Var 2 & $\underline{\text { Match } \operatorname{Var} 3}$ \\
\hline 15031949 & M & CORK & 42 & EN12345678 & M & 0 & 15031949MCORK42EN12345678M0 & 15031949MCORK42EN12345678M & 15031949MCORK42EN12345678 \\
\hline 11021945 & $\mathrm{~F}$ & LIMERICK & 31 & EN52345679 & $\mathrm{s}$ & 1 & 11021945FLIMERICK31EN523456791 & 11021945FLIMERICK31EN52345679S & 11021945FLIMERICK3IEN52345679 \\
\hline 21111954 & M & DUBLIN & 25 & EN52795680 & $\mathrm{o}$ & 2 & 21111954MDUBLIN25EN527956802 & 21111954MDUBLIN25EN527956800 & 21111954MDUBLIN25EN52795680 \\
\hline 19051964 & M & CARLOW & 55 & EN32795681 & D & 2 & 19051964MCARLOW55EN327956812 & 19051964MCARLOW55EN32795681D & 19051964MCARLOW55EN32795681 \\
\hline 22091966 & M & GALWAY & 82 & EN22795682 & M & 3 & 22091966MGALWAY82EN227956823 & 22091966MGALWAY82EN22795682M & 22091966MGALWAY82EN22795682 \\
\hline 24031971 & $\mathrm{~F}$ & CAVAN & 84 & EN52795683 & M & 0 & 24031971FCAVAN84EN527956830 & 24031971FCAVAN84EN52795683M & 24031971FCAVAN84EN52795683 \\
\hline 28021977 & $\mathrm{~F}$ & DUBLIN & 71 & EN84355684 & $\mathrm{s}$ & 1 & 28021977FDUBLIN71EN843556841 & 28021977FDUBLIN71EN84355684S & 28021977FDUBLIN7IEN84355684 \\
\hline 30061990 & $\mathrm{~F}$ & KERRY & 35 & EN73795687 & M & 1 & 30061990FKERRY35EN737956871 & 30061990FKERRY35EN73795687M & 30061990FKERRY35EN73795687 \\
\hline
\end{tabular}

\subsection{ADS (Public Sector Administrative Datasets)}

The records in the master Public Sector Administrative Dataset (ADS) also contained all the above variables used in Census to create the matching variables (Matchvar1 Matchvar10). Therefore the matching variables created in the ADS were used to match to the same variable in the Census.

\subsection{Incremental Matching Process}

To match both datasets (Census to ADS) the matching variables (Matchvar1 Matchvar10) were used. 
$\underline{\text { First Matching (using Matchvarl) }}$

In practice, duplicates will occur when the Unique Identifier (Matchvarl) is created. This can be due to errors in coding. Therefore in the dataset linking process, each dataset (Census and the ADS) is edited to extract records where the Matchvar1 is unique. If there are duplicate occurrences of Matchvarl, then these records are deleted from the matching process. The two datasets (Census and the ADS) were matched using Matchvarl. This yielded a match of 307,300 Census records to the ADS dataset.

\section{Second Matching (using Matchvar2)}

In the second stage of matching, the remaining unmatched records in each dataset (Census and the ADS) are edited to extract records where the variable Matchvar2 is unique. Only unique occurrences of Matchvar2 are used to match both datasets. This yielded a match of 75,400 Census records to the ADS dataset.

Third and consecutive matches (Matchvar3 to Matchvar11)

The matching process continued in this incremental process using Matchvar3 up to Matchvar10. This yielded a total of 797,100 Census records to the ADS dataset.

Figure 5: Incremental Matching Process

\begin{tabular}{|c|l|r|}
\hline $\begin{array}{c}\text { Unique } \\
\text { Identifier } \\
\text { (UI) }\end{array}$ & Variables constituting UI & $\begin{array}{c}\text { No. of } \\
\text { Records } \\
\text { Linked }\end{array}$ \\
\hline Matchvar1 & (CBRno|DoB|sex|NACE2|PP|County|MS) & 307,393 \\
\hline Matchvar2 & (CBRno|DoB|sex|NACE2|PP|County) & 75,410 \\
\hline Matchvar3 & (CBRno|DoB|sex|NACE2|PP|MS) & 29,854 \\
\hline Matchvar4 & (CBRno|DoB|sex|NACE2|PP) & 14,885 \\
\hline Matchvar5 & (DoB|sex|NACE2|PP|County|MS) & 47,963 \\
\hline Matchvar6 & (DoB|sex|NACE2|PP|County) & 16,898 \\
\hline Matchvar7 & (DoB|sex|NACE2|PP|MS) & 25,996 \\
\hline Matchvar8 & (DoB|sex|NACE2|PP) & 15,170 \\
\hline Matchvar9 & (DoB|sex|NACE2|County|MS) & 204,099 \\
\hline Matchvar10 & (DoB|sex|NACE2|County) & 59,102 \\
\hline & Total no. of records linked & $\mathbf{7 9 6 , 7 7 0}$ \\
\hline
\end{tabular}

\subsection{False Positives}

False positives can occur in the matching process if a variable is incorrect on one of the datasets. For example is the county variable has not been updated on the Social Welfare dataset then the county will be different on the person's record on Census. Similarly, if the NACE code is incorrect on either dataset, then it will not match a person to their correct record. 


\section{Mathematical Representation of Identity Correlation Approach (ICA)}

Creating a Unique Identifier (UI) for each record using the Identity Correlation Approach (ICA) will result in a perfect match of records across two datasets, if there is a sufficient overlap of variables on both datasets. The probability of matching records across two datasets can be calculated by a formula known as the Matching Rate of Unique Identifier (MRUI). This is illustrated in Table 1.

Table 1: Matching Rate for Unique Identifier

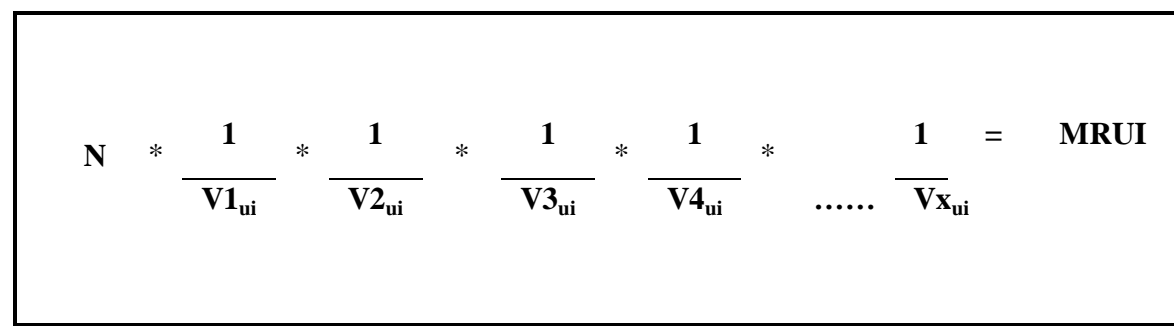

Where:

$\mathrm{N}=$ Population, $\mathrm{V}=$ Variable, $\mathrm{x}=$ no. of variables

$\mathrm{ui}=$ Uniqueness Factor. $\mathrm{ui}=$ no. of classes where variable is distributed evenly across all classes

MRUI The Matching Rate for Unique Identifier (MRUI) is the ability to identify a unique record in a dataset, given the combination of variables used to deduce the record. Mathematically it is assumed that variables are discreet (non-dependent).

\section{Results \& Conclusion}

Results for matching Census records to Administrative Datasets are given in Figure 6, classified by NACE industrial sector. The lower rate of matching in some sectors (e.g. Construction) can be attributed to records not being updated for certain variables. If the theoretical MRUI value indicates a perfect match, but this is not reflected in practice, then there are issues with coding or with records not being updated. 
Figure 6: Employee Population Coverage 2011 - Census \& Administrative Datasets Matched

\begin{tabular}{|lr|}
\hline Nace Economic Sector & $\begin{array}{r}\text { No. } \\
\text { Employees } \\
\text { Total }\end{array}$ \\
B-E Industry & 55 \\
F Construction & 26 \\
G Wholesale and retail trade & 44 \\
H Transporation and Storage & 51 \\
I Accommodation and Food Services & 31 \\
J Information and communication & 52 \\
K-L Financial, insurance, etc. & 61 \\
M Professional, scientific \& technical & 39 \\
N Administrative and support services & 26 \\
O Public administration \& defence & 69 \\
P Education & 63 \\
Q Health \& social work & 46 \\
R-S Arts, entertainment, other services & 41 \\
Total & 47 \\
\hline
\end{tabular}

\subsection{Impact of ICA Data Matching}

The ICA (Identity Correlation Approach) enabled 50\% of the employee population in Ireland (750,000 of 1.5 million employees) to be matched to the Census 2011 dataset, as part of the SESADP. This enabled the Census dataset to provide variables for the SES (e.g. education level and occupation). Outputs from the SESADP produced the SES data for 2011 to 2014 and avoided having to do an expensive business Survey. IT and statistical infrastructure are now in place to produce the SES on an annual basis going forward, reducing costs from $€ 1.6$ million annually to $€ 0.1$ million. A Cost/Benefit Analysis of the SESADP is given in Figure 8.

\subsection{Data Quality}

An analysis of the data was undertaken to determine if the ICA matched the Census correctly to the other administrative data sources (ADS). There was a $90 \%$ correlation with the individual's employer name on Census with the employer name on the Business Register. The $10 \%$ with a different business name were eliminated as false positives. In Figure 9 a distribution of employees by age group and NACE in the Census dataset shows a very good comparison with the SESADP (similar results were obtained for education, occupation \& gender comparisons). 
Figure 8: Cost/Benefit Analysis of the SESADP

\begin{tabular}{|l|l|l|l|}
\hline & $\begin{array}{c}\text { Business Survey } \\
\text { former NES }\end{array}$ & \multicolumn{1}{|c|}{ SESADP Project } & \multicolumn{1}{c|}{ SESADP (Annual) } \\
\hline Survey Type & $\underline{\text { Annual Survey }}$ & $\underline{\text { Data for 4 years }}$ & $\begin{array}{l}\text { Annual basis - going } \\
\text { forward }\end{array}$ \\
\hline Reference period & Years 2002 to 2009 & 2011 to 2014 & 2015 onwards \\
\hline Cost & $€ 1.6$ million p.a. & $€ 0.4 \mathrm{~m}$ & $€ 0.1 \mathrm{~m}$ p.a. \\
\hline Timeliness & T+18 & 2 years to develop & \multicolumn{1}{|c|}{ + 10} \\
\hline Data edits & Data Edits & $\begin{array}{l}\text { No edits - Revenue } \\
\text { data }\end{array}$ & $\begin{array}{l}\text { No edits - Revenue } \\
\text { data }\end{array}$ \\
\hline Sample size & $65 \mathrm{k}$ & $800 \mathrm{k}$ & $800 \mathrm{k}+$ \\
\hline $\begin{array}{l}\text { Coverage } \\
\text { employee } \\
\text { population }\end{array}$ & $4 \%$ & $50 \%$ & $50 \%+$ \\
\hline Burden & 70,000 employees & None & None \\
\hline Burden & 5,000 enterprises & None & None \\
\hline Staff Nos. & 15 FTEs & 4 & 2 \\
\hline Savings & - & $€ 6.0 \mathrm{~m}$ & $€ 1.5 \mathrm{~m}$ p.a. \\
\hline
\end{tabular}

Figure 9: Employees Nos. in SESADP compared to Census dataset by Nace Sector and Age Group 2011

\begin{tabular}{|c|c|c|c|c|c|c|}
\hline \multirow{3}{*}{ NACE Economic Sector } & \multicolumn{6}{|c|}{ \% difference in employee nos. } \\
\hline & \multicolumn{6}{|c|}{ Age Group in years } \\
\hline & $15-24$ & 25-29 & 30-39 & $40-49$ & $50-59$ & $\begin{array}{c}60 \text { and } \\
\text { over }\end{array}$ \\
\hline & $\%$ & $\%$ & $\%$ & $\%$ & $\%$ & $\%$ \\
\hline B-E Industry & -1 & -1 & 2 & 1 & 0 & -1 \\
\hline F Construction & -1 & -1 & 3 & 0 & -1 & -1 \\
\hline G Wholesale \& Retail Trade; Repair of Motor & & & & & & \\
\hline Vehicles and Motorcycles & 0 & -1 & 1 & 1 & 0 & -1 \\
\hline H Transportation and Storage & -1 & -1 & 0 & 2 & 1 & -1 \\
\hline I Accomodation and Food Service Activities & -1 & -1 & 2 & 1 & 0 & -1 \\
\hline J Information and Communication & -1 & -2 & 3 & 0 & 1 & -1 \\
\hline K-L Financial, Insurance and Real Estate & -1 & 0 & 3 & 0 & 0 & -1 \\
\hline M Professional, Scientific and Technical & & & & & & \\
\hline Activities & 0 & 1 & 3 & -1 & -2 & -1 \\
\hline N Administrative and Support Service Activities & 0 & 1 & 4 & 0 & -2 & -2 \\
\hline $\begin{array}{l}\text { O Public Administration and Defence; } \\
\text { Compulsory Social Security }\end{array}$ & -1 & -1 & 2 & 1 & 1 & 1 \\
\hline $\begin{array}{l}\text { P Education } \\
\text { Pompulsory social security }\end{array}$ & $\begin{array}{l}-1 \\
-2\end{array}$ & -5 & 2 & 1 & $\begin{array}{r}-1 \\
-1\end{array}$ & $\begin{array}{r}0 \\
-1 \\
-1\end{array}$ \\
\hline Q Human Health and Social Activities & 0 & -1 & 1 & 1 & -1 & $\begin{array}{c}0 \\
-1\end{array}$ \\
\hline R-S Arts, entertainment, recreation and other & 0 & 1 & 1 & 1 & -1 & -2 \\
\hline
\end{tabular}




\section{References}

McCormack,K (2015). Constructing structural earnings statistics from administrative datasets: Structure of earnings survey - Administrative data project. The Statistics Newsletter - OECD, 62, 3-5 .

McCormack,K. \& Smyth,M. (2015). Constructing structural earnings statistics from administrative datasets. New Techniques and Technologies for Statistics (NTTS) 2015. Collaboration in Research and Methodology for Official Statistics ${ }^{1}$.

McCormack,K. \& Smyth,M. (2015). Specific Analysis of the Public/Private Sector Pay Differential for National Employment Survey 2009 \& 2010 Data. Research Paper. Central Statistics Office, Ireland ${ }^{3}$

NACE is the "statistical classification of economic activities in the European Community" 9 National Employment Survey 2007 (2009), Central Statistics Office, Ireland ${ }^{6}$.

National Employment Survey 2008 and 2009 (2011), Central Statistics Office, Ireland 5.

National Employment Survey 2009 and 2010 Supplementary Analysis (2012), Central Statistics Office, Ireland ${ }^{4}$.

The European Union Structure of Earnings Survey (SES) in accordance with Council Regulation $n^{\circ} 530 / 1999$ is conducted in the 28 Member States of the European Union as well as candidate countries and countries of the European Free Trade Association (EFTA) ${ }^{7}$.

The Personal Public Service Number (PPSN) is a unique reference number that allows individuals access social welfare benefits, public services and information in Ireland. State agencies that use PPSNs to identify individuals include the Department of Social Protection, the Revenue Commissioners and the Health Service Executive (HSE). ${ }^{2}$ 